\title{
Correlates of diarrhoea among children below the age of 5 years in Sudan
}

\author{
*Siziya $\mathrm{S}^{1}$, Muula AS ${ }^{2}$, Rudatsikira $\mathrm{E}^{3}$
}

1. Public Health Unit, Clinical Sciences Department, School of Medicine, Copperbelt University, Ndola, Zambia

2. Department of Community Health, College of Medicine, University of Malawi, Blantyre, Malawi

3. School of Health Professions, Andrews University, Michigan, United States of America

\begin{abstract}
Background: The Millennium Development Goals recognise child health and survival as an important socio-development issue.

Objective: To determine the correlates of diarrhoea among children aged below 5 years in north Sudan.

Methods: We conducted secondary data analysis of the Sudan Multiple Cluster Indicators Survey II.

Results: Altogether, 23,295 children were included in the survey. Half (50.0\%) of the children were males, and $22.5 \%$ of them were of age less than one year. Boys were $3 \%(\mathrm{p}=0.044)$ more likely to have diarrhoea compared to girls. Compared with the oldest age group (48-59 months), children less than 6 months of age and those aged 36-47 months had $25 \%$ and $18 \%$ lower prevalence of diarrhoea, respectively, while children aged 6-24 months and those aged 24-35 months had 1.5 fold and 1.17 fold higher prevalence of diarrhoea. Children in urban areas were $6 \%$ more likely to have diarrhoea. Children from households with 1 or 2 people per room were $8 \%$ less likely to have diarrhoea compared to children from households with more than 3 people per room.

Conclusion: Diarrhoea was associated with child's age, gender, and social status. Our findings provide a useful baseline for interventions and comparisons with future studies.

Keywords: Sudan, diarrhoea, child health, morbidity, under-five

African Health Sciences 2013; 13(2): 376 - 383 http:/ /dx.doi.org/10.4314/ahs.v13i2.26
\end{abstract}

\section{Introduction}

Reducing child mortality is one of the Millennium Development Goals (MDGs). Diarrhoea continues to be a leading cause of child morbidity and mortality in the developing world ${ }^{1,2}$. Sudan has one of highest prevalence rates of diarrhoea and Global Acute Malnutrition. In one study by Karrar and $\mathrm{Omer}^{3}$, the incidence of diarrhea in a village near Khartoum was 217 episodes per 100 children per year, and was one of the three commonest causes of morbidity. In a 2000 Multiple Indicator Cluster Survey report, $28 \%$ of children below the age of 5 years in north Sudan had diarrhoea in the two weeks prior to the survey, varying from $40 \%$ in Blue Nile to $19 \%$ in South Kordofan ${ }^{4}$.

*Corresponding author:
Prof Seter Siziya
Department of Clinical Sciences, School of
Medicine
The Copperbelt University
P O Box 71191
Ndola, Zambia
Tel: 260-955-752646
Email: ssiziya@gmail.com

Risk factors for diarrhoea among children include age ${ }^{5}, \operatorname{sex}^{6,7}$, geographic location ${ }^{8}$, drinking from unprotected water supply ${ }^{9}$, and household economic status ${ }^{10}$. While poor sanitation, limited access to potable water, inappropriate breastfeeding practices contribute to the burden of disease, there continues to be the need to further document the socio-demographic correlates of diarrhoea in order to inform policy and programmatic interventions that have potential to stem the prevalence of the condition.

Although many studies (including cohort and case control studies) have been conducted in developed and developing countries, most of these studies were based on small hospital or community based studies. Further, prevalence and correlates for diarrhoea may vary with season, geographical area, and between countries. We are not aware of any study on the correlates of diarrhoea that was conducted in Sudan on a larger scale. Hence, the aim of this study was to assess the factors associated with diarrhea using a large sample size from a community-based survey. The hypothesis was to assess if factors known to be associated with 
childhood diarrhoea in other settings were also associated with diarrhoea in north Sudan. Further, we wanted to assess what was the strength of association if we found that the selected independent variables were indeed associated with childhood diarrhoea.

\section{Methods}

This study is based on secondary analysis of the Sudan Multiple Cluster Indicators Survey II (MICS II) conducted in 2000. The survey's design allowed calculation of estimates for a wide range of socioeconomic indicators at the national level, state, urbanrural setting as well as between north and south Sudan. Sixteen states in the north and the three main towns in the south (Juba, Malakal and Wau comprising one state) were included in the survey.

A total of 26,810 households (25200 from north Sudan, and 1620 from south Sudan) were selected for the survey. Altogether, 25183 households were interviewed, giving a response rate of $99.9 \%$. In the households that were selected, 23540 children aged 5 years or younger were enlisted. Out of the 23540 enlisted children, 23296 children's questionnaires were completed, giving a response rate of $99 \%$. The current study however was based on north Sudan and comprise the following states: Northern, Red Sea, Kassala, Gadaref, Gazira, Sinnar, White Nile, Khartoum, Northern Kordofan, Southern Kordofan, Western Kordofan, Northern Darfur, Western Darfur, Southern Darfur, Nile River, and Blue Nile.

From 2011, south Sudan has since obtained independence from (north Sudan). At the time of the MICS II, this was one country. We analysed data from the north Sudan because the survey in this part of the country was conducted separately. Further as the socio-demographics and political situations between the north and south differed significantly even when this was one country, we made the decision therefore to separate the north and analyse its data separately. Furthermore, the data set from south Sudan did not have a weighting variable, while data from north Sudan had a weighting variable, and the two data sets could not be merged. We opted for weighted analysis to obtain reliable estimates.

The sample design was a two-stage stratified cluster sample. States and the three southern towns were considered as strata, and were further stratified into urban and rural areas. In rural areas, the village councils and quarter councils in urban areas were considered as the primary sampling units (PSUs) in the first stage of sampling. These PSUs were selected using probability proportional to size. In the second step of sampling, 35 households were systematically selected in each selected PSU.

\section{Questionnaires administration}

The Sudan MICS II questionnaire was adapted from the generic MICS Model Questionnaire. The household component was designed to collect information on household members (including sex, age, and literacy), residence (rural or urban), assets, number of co-residents, number of rooms in the house, water and sanitation. The children's questionnaire included questions on breastfeeding, immunization, and care of illness. The questionnaire was translated into Arabic. Data were collected by trained research assistants in July 2000. Further details of the design and conduct of the MICS survey are described elsewhere (Federal Ministry of Health et al. http://www.childinfo.org/files/sudan.pdf) ${ }^{11,12}$.

\section{Definitions}

Diarrhoea was determined as perceived by mother or caretaker, or as three or more loose or watery stools per day, or blood in stool. The question "Has (name) had diarrhoea in the last two weeks, that is, since (day of the week) of the week before last?" was posed to a mother or caretaker.

Crowding index was defined as the total number of co-residents per household, excluding the newborn infant, divided by the total number of rooms, excluding the kitchen and bathrooms.

A wealth index for a household was computed using assets reported in the asset module of the questionnaire to reflect the living condition. Assets included housing conditions (floor material, number of rooms, fuel type and electricity), possession of durable goods (radio, television set, wall clock, refrigerator, bicycle, motorcycle, motorcar, and foam mattress), possession of land and animals (cultivated land, cattle, and goat/sheep), and access to necessities (meat, milk, and sugar). Each asset was assigned a weighting value using principal component analysis. A household was assigned a standardized score for each owned asset. For each household, these scores were summed and a household was ranked into five wealth quintiles i.e. the lowest quintile being the poorest and the highest quintile being the richest.

A child was considered to have complete vaccination status if he or she received all the following vaccinations before the age of one year: BCG and 
OPV0 at birth, OPV1, DPT1 and Hepatitis B at 6 weeks, OPV2, DPT2 and Hepatitis B at 10 weeks, OPV3, DPT3 and Hepatitis B at 14 weeks; and Measles at 9 months ${ }^{13}$. Because about $42 \%$ of births in Sudan are not registered ${ }^{4}$ information from both the immunization card and maternal report were considered in determining whether a child was immunized or not. Caretakers were probed to report vaccinations that did not appear on the card or when a child did not have a card.

Data on hygiene and sanitary were obtained using the following questions: What is the main source of drinking water for members of your household? The possible responses were: piped into dwelling, piped into yard or plot, public tap, tube well/ borehole with pump, protected dug well, protected spring, rainwater collection, bottled water, unprotected dug well, unprotected spring, pond, river or stream, tanker-truck, vendor, other (specify), or no answer or don't know. During the analysis, these responses were grouped into piped, protected well and unprotected well/river. What kind of toilet facility does your household use? The possible responses were: pour flush latrine (water seal type), improved pit latrine (e.g. VIP), traditional pit latrine, open pit, bucket, other (specify), or no facility or bush or field. These responses were further classified into flush toilet, traditional pit latrine, and no facility. What happens with the stools of young children (03 years) when they do not use the latrine or toilet facility? The possible responses were: children always use toilet or latrine, thrown into toilet or latrine, thrown outside the yard, buried in the yard, not disposed of or left on the ground, other (specify), or no young children in household. The following categories were used during the analysis: thrown into toilet or latrine, thrown outside the yard, buried in the yard, and left on the ground.

\section{Data analysis}

Weighted prevalence of the main outcome (reported childhood diarrhoea in the past 2 weeks) and sociodemographic characteristics were calculated. Logistic regression analysis was used to assess associations between reported diarrhoea in an under-five child (outcome variable) and independent variables which included: the child's age, sex, residence status (rural or urban), crowding in the household, maternal education, wealth index and availability of sanitation facilities. The independent variables were identified from the literature as associated with diarrhoea: age, sex, residence status, crowding index, maternal education, wealth index and the availability of sanitation facilities. We used a backward variable selection method to enter explanatory variables into the model. The cut-off point for statistical significance was set at the $5 \%$ level. A variable was removed from the model when the level of significance was greater than $5 \%$. The final model was, thus, adjusted for all the factors in the model.

\section{Results}

Data for analysis was available from 23,295 children of age less than 5 years. Overall, $58.8 \%$ of the mothers had no formal education. About half $(50.9 \%)$ of the respondents lived in rural areas. About 1 in 5 of the participants belonged to the poorest wealth index (quintile). Slightly over a third of the households had no toilet facility (38.0\%). About 3 in 4 of the children had incomplete vaccination status $(72.4 \%)$, and $27.8 \%$ of the children were reported to have had diarrhoea the previous two weeks to the survey. The rest of the sociodemographic distributions are shown in table 1.

\section{Correlates for diarrhoea}

The following factors were significantly associated with diarrhoea in bivariate analyses (table 2): Sex and age of child, area of residence, crowding and wealth index, main source of water, toilet facility, and vaccination status. However, in multivariate analysis, only sex and age of child, area of residence, and crowding and wealth index remained significantly associated with the outcome (table 2).

In multivariate analysis, male children were $3 \%(\mathrm{p}=0.044)$ more likely to have diarrhoea compared to female children. Compared with the oldest age group (48-59 months), children less than 6 months of age and those aged 36-47 months had $25 \%$ and $18 \%$ lower prevalence of diarrhoea, respectively, while children aged 6-24 months and those aged 24-35 months had 1.5 fold and 1.17 fold higher prevalence of diarrhoea. Respondents residing in urban areas were $6 \%$ less likely to have children with diarrhoea. Children from households with 1 or 2 people per room were $8 \%$ less likely to have diarrhoea compared to children from households with more than 3 people per room. While participants in the fourth wealth index were $8 \%$ more likely to have diarrhoea compared to participants in the richest wealth index, the prevalence of diarrhoea in the poorest, second and middle wealth indices was not significantly different from the prevalence in the richest wealth index. 
Table 1: Socio-demographic characteristics of the children in the north of Sudan, 2000 MICS

\begin{tabular}{|c|c|c|c|}
\hline Characteristic & $\begin{array}{l}\text { Total } \\
\mathrm{n}^{*}\left(\%^{* *}\right)\end{array}$ & $\begin{array}{l}\text { Male } \\
\mathrm{n}^{*}\left(\%{ }^{* *}\right)\end{array}$ & $\begin{array}{l}\text { Females } \\
\mathrm{n}^{*}\left(\%{ }^{* *}\right)\end{array}$ \\
\hline Sex of child & $23290(100)$ & $11690(50.0)$ & $11600(50.0)$ \\
\hline \multicolumn{4}{|l|}{ Age of child (months) } \\
\hline$<6$ & $2726(11.4)$ & $1364(11.1)$ & $1362(11.7)$ \\
\hline $6-11$ & $2573(11.1)$ & $1327(11.3)$ & $1246(10.8)$ \\
\hline $12-23$ & $3618(16.0)$ & $1860(16.5)$ & $1757(15.4)$ \\
\hline $24-35$ & $4968(21.4)$ & $2463(21.1)$ & $2504(21.7)$ \\
\hline $36-47$ & $5090(21.9)$ & $2532(22.0)$ & $2558(21.7)$ \\
\hline $48-59$ & $4319(18.3)$ & $2144(18.0)$ & $2173(18.6)$ \\
\hline \multicolumn{4}{|c|}{ Maternal formal education } \\
\hline None & $14640(58.8)$ & $7317(58.3)$ & $7321(59.4)$ \\
\hline Primary & $410(1.7)$ & $96(1.7)$ & $214(1.8)$ \\
\hline Secondary & $8172(39.4)$ & $4142(40.0)$ & $4027(38.8)$ \\
\hline \multicolumn{4}{|l|}{ Area of residence } \\
\hline Urban & $8205(49.1)$ & $4116(49.0)$ & $4086(49.2)$ \\
\hline Rural & $15090(50.9)$ & $7574(51.0)$ & $7514(50.8)$ \\
\hline \multicolumn{4}{|l|}{ Crowding index } \\
\hline$<2.00$ & 4394 (19.1) & $2189(19.2)$ & 2205 (19.1) \\
\hline $2.01-3.00$ & $5781(24.8)$ & $2878(25.0)$ & $2902(24.6)$ \\
\hline$>3.00$ & $13117(56.1)$ & $6623(55.8)$ & $6493(56.3)$ \\
\hline \multicolumn{4}{|l|}{ Wealth index (quintiles) } \\
\hline Poorest & $5400(19.7)$ & $2652(19.3)$ & $2748(20.0)$ \\
\hline Second & $5293(20.4)$ & $2650(20.3)$ & $2642(20.6)$ \\
\hline Middle & $5833(22.7)$ & $2945(22.7)$ & $2887(22.8)$ \\
\hline Fourth & $3955(20.8)$ & $2003(20.9)$ & $1951(20.6)$ \\
\hline Richest & $2814(16.4)$ & $1440(16.8)$ & $1372(16.0)$ \\
\hline \multicolumn{4}{|l|}{ Ever breastfed } \\
\hline No & $500(2.3)$ & $232(2.2)$ & $262(2.4)$ \\
\hline Yes & $22742(97.7)$ & $11427(97.8)$ & $11310(97.6)$ \\
\hline \multicolumn{4}{|l|}{ Main source of water } \\
\hline Piped & $5784(35.3)$ & $2908(35.6)$ & $2874(35.0)$ \\
\hline Protected well & $7152(30.7)$ & $3562(30.8)$ & $3590(30.7)$ \\
\hline Unprotected well/river & $8814(33.9)$ & $4404(33.6)$ & $4410(34.3)$ \\
\hline \multicolumn{4}{|l|}{ Toilet facility } \\
\hline Flush toilet & $1239(6.8)$ & $619(6.9)$ & $620(6.7)$ \\
\hline Traditional pit latrine & $11292(55.2)$ & $5665(55.3)$ & $5625(55.0)$ \\
\hline No facility & $9902(38.0)$ & $4967(37.8)$ & 4935 (38.2) \\
\hline \multicolumn{4}{|l|}{ Disposal of children' stool } \\
\hline Thrown in toilet/pit latrine & $11649(60.5)$ & $5834(60.7)$ & $5813(60.2)$ \\
\hline Thrown outside the yard & $8511(34.6)$ & $4262(34.3)$ & $4249(34.9)$ \\
\hline Buried in the yard & $758(3.1)$ & $362(3.0)$ & $396(3.3)$ \\
\hline Left on the ground & $313(1.8)$ & $164(1.9)$ & $149(1.7)$ \\
\hline \multicolumn{4}{|l|}{ Vaccination status } \\
\hline Incomplete & $17912(74.8)$ & $9002(74.7)$ & 8905 (74.8) \\
\hline Complete & $5383(25.2)$ & $2688(25.3)$ & $2695(25.2)$ \\
\hline \multicolumn{4}{|l|}{ Diarrhoea } \\
\hline No & $16642(72.4)$ & 8277 (71.6) & $8361(73.1)$ \\
\hline Yes & $6563(27.8)$ & $3377(28.4)$ & $3185(26.9)$ \\
\hline
\end{tabular}

$\mathrm{n}^{*}$ unweighted frequency, $\% *$ weighted percent 
Table 2: Correlates of diarrhoea among children aged less than 5 years in the north of Sudan, 2000 MICS

\begin{tabular}{|c|c|c|}
\hline Characteristic & $\mathrm{OR}^{*}\left(95 \% \mathrm{CI}^{* *}\right)$ & $\operatorname{AOR}^{* * *}(95 \% \mathrm{CI})$ \\
\hline \multicolumn{3}{|l|}{ Sex } \\
\hline Male & $1.08(1.02,1.14)$ & $1.03(1.00,1.06)^{\mathrm{a}}$ \\
\hline Female & 1 & 1 \\
\hline \multicolumn{3}{|l|}{ Age of child (months) } \\
\hline$<6$ & $0.78(0.72,0.84)$ & $0.75(0.69,0.82)$ \\
\hline $6-11$ & $1.45(1.35,1.56)$ & $1.47(1.36,1.59)$ \\
\hline $12-23$ & $1.51(1.42,1.61)$ & $1.52(1.42,1.63)$ \\
\hline $24-35$ & $1.16(1.10,1.23)$ & $1.17(1.10,1.24)$ \\
\hline $36-47$ & $0.82(0.78,0.88)$ & $0.82(0.77,0.87)$ \\
\hline $48-59$ & 1 & 1 \\
\hline \multicolumn{3}{|l|}{ Maternal formal education } \\
\hline None & $1.04(0.98,1.10)$ & - \\
\hline Primary & $1.04(0.83,1.30)$ & \\
\hline Secondary & 1 & \\
\hline \multicolumn{3}{|l|}{ Area of residence } \\
\hline Urban & $0.93(0.91,0.96)$ & $0.94(0.90,0.97)$ \\
\hline Rural & 1 & 1 \\
\hline \multicolumn{3}{|l|}{ Crowding index } \\
\hline$<2.00$ & $0.93(0.88,0.98)$ & $0.92(0.87,0.98)$ \\
\hline $2.01-3.00$ & $1.02(0.97,1.06)$ & $1.02(0.97,1.07)$ \\
\hline$>3.00$ & 1 & 1 \\
\hline \multicolumn{3}{|l|}{ Wealth index (quintiles) } \\
\hline Poorest & $1.06(1.00,1.12)$ & $1.02(0.96,1.09)$ \\
\hline Second & $1.08(1.02,1.14)$ & $1.06(1.00,1.13)^{\mathrm{b}}$ \\
\hline Middle & $1.06(1.00,1.12)$ & $1.05(0.99,1.11)$ \\
\hline Fourth & $1.05(1.00,1.12)$ & $1.08(1.01,1.14)$ \\
\hline Richest & 1 & 1 \\
\hline \multicolumn{3}{|l|}{ Ever breastfed } \\
\hline No & $1.09(0.99,1.20)$ & - \\
\hline Yes & 1 & \\
\hline \multicolumn{3}{|l|}{ Main source of water } \\
\hline Piped & $0.90(0.86,0.94)$ & - \\
\hline Protected well & $1.06(1.02,1.11)$ & \\
\hline Unprotected well/river & 1 & \\
\hline \multicolumn{3}{|l|}{ Toilet facility } \\
\hline Flush toilet & $0.84(0.77,0.91)$ & - \\
\hline Traditional pit latrine & $1.09(1.04,1.15)$ & \\
\hline No facility & 1 & \\
\hline \multicolumn{3}{|l|}{ Disposal of children' stool } \\
\hline Thrown in toilet/pit latrine & $0.96(0.89,1.04)$ & - \\
\hline Thrown outside the yard & $1.05(0.97,1.14)$ & \\
\hline Buried in the yard & $0.87(0.76,1.01)$ & \\
\hline Left on the ground & 1 & \\
\hline \multicolumn{3}{|l|}{ Vaccination status } \\
\hline Incomplete & $1.04(1.01,1.08)$ & - \\
\hline Complete & 1 & \\
\hline
\end{tabular}




\section{Discussion}

In a study of under-five children in north Sudan, we found that being a boy was positively associated with diarrhoea even though a $3 \%$ increase in odds of having diarrhoea among males compared to females may not be of public health importance. This finding, which contradicts that of el Samani et $\mathrm{al}^{14}$ who found that the risk of diarrhoea was higher for females than males in a rural Sudanese community, is consistent with previous reports from Guinea Bisau ${ }^{9}$ and Republic of Congo ${ }^{5}$. That boys would be affected more compared to girls deserves further exploration and attention in terms of interventions. We are not sure, if as early as under the age of five years, boys are likely to wander off in unsanitary surroundings compared to girls. Boys may also be more vulnerable to diseases than females. A study of paediatric hospital admissions in Hong Kong, Hon and Nelson ${ }^{15}$ reported that males had a consistent excess in admissions of females. Siziya et $\mathrm{al}^{12}$ reported that, among children under five years of age in Iraq, males were more likely to have acute respiratory infection than females. In a study of the male predominance in the incidence of infectious diseases in children, Green (1992) found that the theory of immunodeficiency prevalence among males was not supported by an excess of $2-3 \%$ in overt symptoms ${ }^{16}$.

Findings from our study indicate that participants 6-35 months of age were more likely to have diarrhea than those who were younger or older. This is similar to previous reports from other settings in sub-Saharan Africa ${ }^{5,9,14,16}$. Protection against diarrhoea in the youngest age group may be conferred by several mechanisms such as maternal antibodies against enteric pathogens and current breastfeeding. It is possible that after the age of 6 month, with the introduction of supplementary foods and changing nutritional habits, this protection is lost. The lower prevalence of diarrhoea in the oldest age group may be due to acquired natural immunity.

In this study, overcrowding and living in a rural area were associated with a history of diarrhoea in the past two weeks preceding the survey. ElGilany and Hammad ${ }^{17}$ have reported similar findings from Dakahlia, Egypt. This may due to the fact that rural residents tend to be poorer than urban residents, which impact the level of hygiene, especially in areas where there is a cyclic drought that may be affecting more the vulnerable rural population.
Findings on the association between wealth and diarrhoea have not been consistent. We obtained inconsistent results in the current study with regards to the association between wealth index and diarrhoea because the odds of having diarrhoea were not different between participants in the poorest, second and middle wealth indices on one hand and those in the richest wealth index, while participants in the fourth wealth index were more likely to have diarrhoea compared to those in the richest wealth index. We did not find the same result in the Iraq study ${ }^{18}$ in which we found no association between wealth and diarrhoea. Further, Osumane ${ }^{19}$, Huttly et $\mathrm{al}^{20}$ and El Samani et al ${ }^{21}$ did not find a significant association between diarrhoea and wealth. Contrary to the above findings, Boadi and Kuitunen ${ }^{22}$ reported that children from poor homes had higher diarrheal incidence than their medium wealth and high wealth counterparts. Roots ${ }^{23}$ suggested that wealthy parents may be unable to reduce risk of exposure due to factors beyond their control, such as contaminated community environments or lack of water.

\section{Limitations of the study}

Data that were not obtained from the Child Health card were self-reported by the mother e.g. history of breastfeeding and diarrhoea. We acknowledge the limitation of using the variable "breastfeeding" that was classified as "ever" or "never". A better classification would have been "current", "past", or "never". Unfortunately we did not determine this classification from the available data. Data on anthropometric measurements was not considered in the analysis and our results may be biased to the extent nutritional status was related to diarrhoea in our study population. Other limitations of the study include lack of data on the severity or duration of the outcome. Further, prevalence cases of diarrhoea and not incidence cases were considered in the study, and thus children with fatal illness or some mild cases probably were not included in the survey. Hence, our findings may be biased to the extent severe or mild cases may have differed from those who participated in the survey. To the extent that mothers failed to report accurately, either intentionally or unintentionally, our findings may have been biased. However, we are unable to determine magnitudes or directions of these biases. Although we cannot assign causation on observed associations, the factors identified in this study (age, sex, wealth index) would not have been altered by the diarrheal episode. 
However, to propose causation and not just association may require further information and assessments.

\section{Conclusion}

In a study of under-five children in north Sudan in 2000, we found that diarrhoea was associated with child's age, gender, and social status. Our findings provide a useful baseline for interventions and comparisons with future studies.

\section{Acknowledgements}

We thank UNICEF for making the Sudan Multiple Indicator Cluster Survey II (MICS II) data available to us for analysis. The Sudan MICS II survey was carried out in partnership among the Government of Sudan, UNICEF and the World Bank. None of these organizations however, had any role in the design of the present analysis or decision to publish the findings.

\section{References}

1. Kopek M, Bern C, Guaranty RL. The global burden of diarrhoeal disease, as estimated from studies published between 1992 and 2000. Bull World Health Organ 2003;81:197-204.

2. Lopez AD, Mathers CD, Ezzati M, Jamison DT, Murray CJ. Global and regional burden of disease and risk factors, 2001: systematic analysis of population health data. Lancet 2006;367:1747-1757.

3. Karrar ZA, Omer MI. Morbidity patterns among under-five children in a rural community in Sudan. Trop Geogr Med 1981;33:75-78.

4. Federal Ministry of Health, Central Bureau of Statistics, UNICEF. Multiple indicator cluster survey, 2000 Sudan-Final report. http:// www.childinfo.org/files/sudan.pdf. Accessed 26 August 2012.

5. Mock NB, Sellers TA, Abdoh AA, Franklin RR. Socioeconomic, environmental, demographic and behavioural factors associated with occurrence of diarrhea in young children in the Republic of Congo. Soc Sci Med 1993;36:807816.

6. Muhsen K, Athamna A, Cohen D. Incidence and risk factors of diarrheal diseases among 35 year old Israeli Arab children attending kindergartens. Harefuah 2007;146:341-407.

7. Staat MA, Morrow AL, Reves RR, Bartlett AV, Pickering LK. Diarrhea in children newly enrolled in day-care centers in Houston. Pediatr Infect Dis J 1991;10:282-286.

8. Kazember LN, Namangale JJ. A Bayesian multinomial model to analyse spatial patterns of childhood co-morbidity in Malawi. Eur J Epidemiol 2007;22:545-556.

9. Molbak K, Jensen H, Ingholt L, Aaby P. Risk factors for diarrheal disease incidence in early childhood: a community cohort study from Guinea-Bissau. Am J Epidemiol 1997;146:273282.

10. Kandala NB, Ji C, Stallard N, Stranges S, Cappuccio FP. Morbidity from diarrhoea, cough and fever among young children in Nigeria. Ann Trop Med Parasitol 2008;102:427445.

11. Siziya S, Muula AS, Rudatsikira E, Mataya RH. Correlates of HIV testing among women in Malawi: results from the 2006 Multiple Indictor Cluster Survey. Trop Med Int Health 2008;13:1351-1356.

12. Siziya S, Muula AS, Rudatsikira E. Diarrhoea and acute respiratory infections prevalence and risk factors among under-five children in Iraq in 2000. Rivista Italian di Pediatria 2009;35:8.

13. el Asyed El-TA. Highlights on the expanded program on immunization (EPI) in Sudan. Sudanese J Public Health 2006;2:152-158.

14. el Samani FZ, Willett WC, Ware JH. Predictors of simple diarrhoea in children under 5 yearsa study of a Sudanese rural community. Soc Sci Med 1989;29:1065-1070.

15. Hon KL, Nelson EA. Gender disparity in paediatric admissions. Ann Acad Med Singapore 2006;35:882-888.

16. Green MS. The male predominance in the incidence of infectious diseases in children: a postulated explanation for disparities in the literature. Int J Epidemiol 1992;21:381-386.

17. el-Gilany AH, Hammad S. Epidemiology of diarrhoeal diseases among children under age 5 years in Dakahlia, Egypt. East Mediterr Health J 2005;11:762-775.

18. Siziya S, Muula AS, Rudatsikira E. Diarrhoea and acute respiratory infections prevalence and risk factors among under-five children in Iraq in 2000. Indian J Pediatr 2009;35:8.

19. Osumanu IK. Household environmental and behavioural determinants of childhood diarrhoea morbidity in the Tamale Metropolitan 68. Area (TMA), Ghana. Dan J Geogr 2007;107:59- 
20. Huttly SRA, Blum D, Kirkwood BR, Emeh RN, Feachem RG. The epidemiology of acute diarrhoea in a rural community in Imo State, Nigeria. Trans-Afr Res Trop Med Hyg 1987;81:865-870.

21. el Samani EFZ, Willett WC, Ware JH. Association of malnutrition and diarrhoea in children aged under five years: a prospective follow-up study in a rural Sudanese Community. Am J Epidemiol 1988;128:93-105.
22. Boadi KO, Kuitunen M. Environment, wealth, inequality and the burden of disease in the Accra metropolitan area, Ghana. Int J Environ Health Res 2005;15:193-206.

23. Root GM. Sanitation, community environments and childhood diarrhoea in rural Zimbabwe. J Health Popul Nutr 2001;19:73-82. 